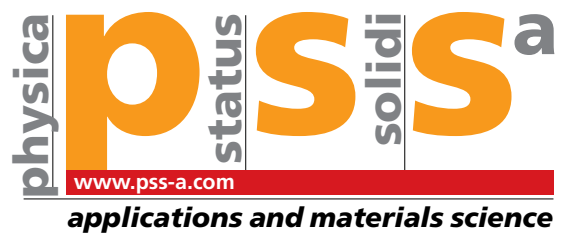

\title{
Effect of composition on the bonding environment of In in InAIN and InGaN epilayers
}

\author{
M. Katsikini ${ }^{* 1}$, F. Pinakidou' ${ }^{2}$ E. C. Paloura', Ph. Komninou', E. Iliopoulos ${ }^{2,3}$, A. Adikimenakis ${ }^{2,3}$, \\ A. Georgakilas ${ }^{2,3}$, and E. Welter ${ }^{4}$ \\ ${ }^{1}$ School of Physics, Aristotle University of Thessaloniki, 54124 Thessaloniki, Greece \\ ${ }^{2}$ Physics Department, University of Crete, 71003 Heraklion-Crete, Greece \\ ${ }^{3}$ Microelectronics Research Group, IESL-FORTH, 71110 Heraklion-Crete, Greece \\ ${ }^{4}$ HASYLAB, Notkestr. 85, 22603 Hamburg, Germany
}

Received 18 November 2007, revised 7 May 2008, accepted 12 May 2008

Published online 18 September 2008

PACS 61.05.cj, 61.66.Dk, 81.05.Ea

* Corresponding author: e-mail katsiki@auth.gr, Phone: +30 2310 998500, Fax: +30 2310998036

We report on the bonding environment of $\mathrm{In}$ in $\operatorname{In}_{\mathrm{x}} \mathrm{Al}_{1-\mathrm{x}} \mathrm{N}$ $(0.07<\mathrm{x}<0.25)$ and $\operatorname{In}_{\mathrm{y}} \mathrm{Ga}_{1-\mathrm{y}} \mathrm{N}(0.7<\mathrm{y}<1)$ epilayers using extended X-ray absorption fine structure (EXAFS) spectroscopy. The EXAFS analysis reveals that the In-N distance, in both the InAIN and the InGaN ternaries, is only weakly dependent on the In content. Contrary to that, the In-cation distances (in the 2nd nearest neighbour shell) have values closer to those predicted by Vegard's law. More specifically, the distribution of the In-cation distances is bimodal with the
In-Ga and In-Al distances being smaller than the In-In distance. The variation of the $\mathrm{In}-\mathrm{Ga}$ and $\mathrm{In}-\mathrm{Al}$ distances with the In content is in agreement with Vegard's law while the In-In distance deviates from the expected values for In fractions smaller than 0.7. The identified composition-dependent variation of the In-N and In-cation distances, indicates that the alloying induced stress in InAIN and InGaN is mainly accommodated by bond angle variation rather than bond length deformation.
1 Introduction The growth of InN samples with reduced impurity concentration resulted to re-evaluation of its energy gap which takes values in the range $0.65-0.9 \mathrm{eV}$, i.e. in the infrared (IR) part of the spectrum [1]. Thus, alloying of InN with GaN and AlN permits the fabrication of light emitting devices (diodes and lasers) that operate in the spectral range from IR to ultraviolet. Furthermore, the fabrication of high-electron mobility transistors (HEMT's) on $\mathrm{In}_{\mathrm{x}} \mathrm{Al}_{1-\mathrm{x}} \mathrm{N} / \mathrm{GaN}$ heterostructures was recently demonstrated [2].

The optical and electronic properties of the alloys depend on the band structure which is in turn affected by the interatomic distances. Growth of group-III nitrides on $\mathrm{Al}_{2} \mathrm{O}_{3}$ results to wurtzite polytypes. Alloying of $\mathrm{InN}$ with AlN or GaN leads to a reduction of the $a$ and $c$ lattice constants, according to Vegard's law, due to the smaller lattice constants of AIN and GaN. Although alloying affects the lattice constants, which are determined by diffraction tech- niques, the nearest neighbour distances are less affected since they are mainly determined by the overlap of the atomic orbitals [3]. Thus, the stress due to the intermixing of In with $\mathrm{Al}$ or $\mathrm{Ga}$ in the cation sublattice is expected to be mainly accommodated by bond angle deformations rather than changes in the bond lengths.

Here we apply extended X-ray absorption fine structure (EXAFS) spectroscopy in order to determine the local bonding environment of $\mathrm{In}$ in $\mathrm{In}_{\mathrm{x}} \mathrm{Ga}_{1-\mathrm{x}} \mathrm{N}$ and $\mathrm{In}_{\mathrm{y}} \mathrm{Al}_{1-\mathrm{y}} \mathrm{N}$ samples. EXAFS maps the oscillatory modulation of the $\mathrm{X}$-ray absorption coefficient above the absorption edge of a core electron shell. The oscillatory behavior of the EXAFS signal appears due to the interference of the outgoing photoelectron wave and the wave scattered by the neighbouring atoms. Therefore it is suitable for the detection of deviations in the distances between In and its nearest neighbours from the values predicted by Vegard's law. 


\section{Growth conditions and experimental details} The studied $\operatorname{In}_{\mathrm{x}} \mathrm{Ga}_{1-\mathrm{x}} \mathrm{N}$ and $\mathrm{In}_{\mathrm{y}} \mathrm{Al}_{1-\mathrm{y}} \mathrm{N}$ films were grown by radio frequency plasma assisted molecular beam epitaxy on $\mathrm{Al}_{2} \mathrm{O}_{3}$ substrates using $\mathrm{GaN}$ and $\mathrm{AlN}$ buffer layers, respectively [4]. The film's composition was determined with high resolution X-ray diffraction. The $100 \mathrm{~nm}$-thick $\mathrm{In}_{\mathrm{x}} \mathrm{Ga}_{1-\mathrm{x}} \mathrm{N}$ epilayers were grown at $400{ }^{\circ} \mathrm{C}$ and have the following composition: IG567 $(x=0.07)$, IG597 ( $x=0.7)$, IG589 $(\mathrm{x}=0.8)$ and IG590 $(\mathrm{x}=0.9)$. The $1.2 \mu \mathrm{m}$-thick InN sample (I643) was grown at $335^{\circ} \mathrm{C}$. The thickness of the $\operatorname{In}_{\mathrm{y}} \mathrm{Al}_{1-\mathrm{y}} \mathrm{N}$ films takes values in the range $0.2-0.3 \mu \mathrm{m}$, they were grown in the temperature range $500-620{ }^{\circ} \mathrm{C}$ and their compositions are: IA857 $(\mathrm{y}=0.07), \operatorname{IA} 836(\mathrm{y}=0.12)$ and IA847 $(\mathrm{y}=0.25)$.

The EXAFS measurements were conducted at the $\mathrm{C}$ and A1 beamlines of the Synchrotron Radiation Laboratory HASYLAB in Hamburg. The In $K$ edge spectra were recorded at room temperature in the fluorescence yield mode using a 7-pixel $\mathrm{Si}(\mathrm{Li})$ fluorescence detector cooled at $77 \mathrm{~K}$. The detector was positioned on the horizontal plane, at right angle to the beam which was impinging on the sample surface with an angle of incidence equal to $55^{\circ}$. In this geometry polarization effects are avoided. The spectra were normalized with the incoming photon flux using the signal of an ionization chamber positioned in front of the sample.

3 Results and discussion $\operatorname{In}_{\mathrm{x}} \mathrm{Ga}_{1-\mathrm{x}} \mathrm{N}$ and $\mathrm{In}_{\mathrm{y}} \mathrm{Al}_{1-\mathrm{y}} \mathrm{N}$ alloys, especially those grown on $\mathrm{Al}_{2} \mathrm{O}_{3}$, crystallize in the hexagonal wurtzite structure (group symmetry: $\mathrm{P} 6_{3} \mathrm{mc}$ ). The $a$ and $c$ lattice constants take values intermediate to those corresponding to the binary constituents, according to Vegard's law. The lattice constants depend on the growth conditions and they are affected by the presence of point and extended defects. Previously published values for the hexagonal lattice constants are: $a_{\mathrm{InN}}=3.54 \AA, a_{\mathrm{GaN}}$ $=3.189 \AA, a_{\mathrm{AIN}}=3.11 \AA, c_{\mathrm{InN}}=5.70 \AA, c_{\mathrm{GaN}}=5.185 \AA$, $c_{\text {AIN }}=4.98 \AA[5]$. Another important structural parameter of the wurtzite structure is the $u$ parameter which corresponds to the $\mathrm{z}$-component of the relative displacement of the cation and nitrogen sublattices. The $u$ parameter is a measure of the trigonal distortion of the tetrahedra.

Prior to analysis, the In $K$ edge EXAFS spectra were subjected to subtraction of the atomic background and normalization. Transformation from the energy space to the photoelectron wavenumber $(\mathrm{k})$ space results to the $\chi(\mathrm{k})$ spectrum. The Fourier Transform of the $\chi(\mathrm{k})$ spectrum in the $\mathrm{R}$-space is analogous to the radial distribution function around the absorbing atom. In order to extract structural parameters of the local bonding environment of the absorbing atom, the spectra are fitted using proper photoelectron scattering paths that contain $\mathrm{k}$-dependent values of the amplitude and the phase of the backscattering function as well as of the mean free path of the photoelectron. The theoretical paths were constructed with the FEFF 8 package [6], assuming a hexagonal unit shell with lattice constants obey- ing Vegard's law and using a $u$ parameter equal to $3 / 8$. The $\mathrm{k}^{2}$ weighted $\chi(\mathrm{k})$ spectra of the $\mathrm{InN}$ and the $\operatorname{In}_{\mathrm{x}} \mathrm{Ga}_{1-\mathrm{x}} \mathrm{N}$ samples were simultaneously fitted in R-space using commonly iterated amplitude reduction factor and shift of the energy origin for the three nearest neighbour $(n n)$ shells: The first shell consists of $4 \mathrm{~N}$ atoms while the second and third consist of $12 \cdot(1-x)$ Ga and $12 \cdot x$ In atoms, respectively. The spectra of the $\operatorname{In}_{\mathrm{y}} \mathrm{Al}_{1-\mathrm{y}} \mathrm{N}$ samples were fitted in a similar way, the only difference being the different shift of the energy origin that was necessary in order to fit the spectrum of the IA847 sample. During the fitting the coordination numbers were kept fixed while the $n n$ distances and the Debye-Waller factors (DWF) were iterated.

The fitted spectra of the InN and $\operatorname{In}_{\mathrm{x}} \mathrm{Ga}_{1-\mathrm{x}} \mathrm{N}$ samples in the k- and R-space are shown in Figs. 1 and 2, respectively.

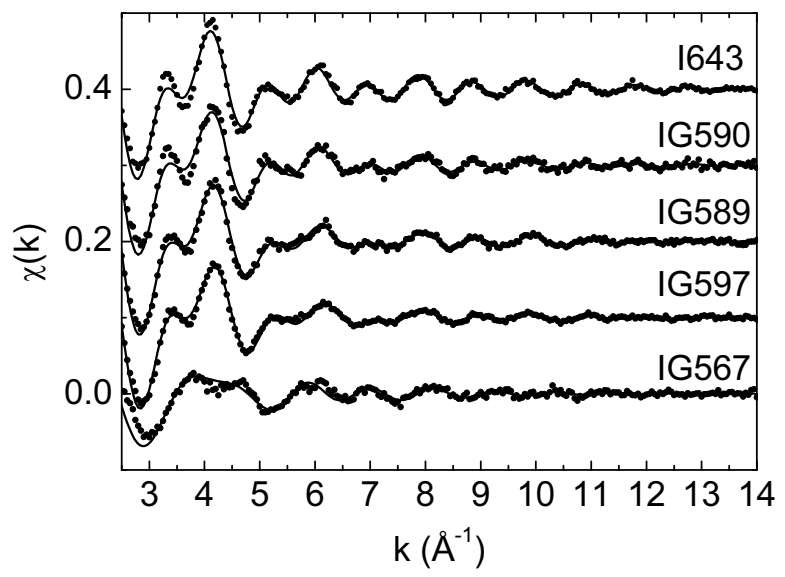

Figure $1 \chi(\mathrm{k})$ spectra of the $\mathrm{InN}(\mathrm{I} 643)$ and $\operatorname{In}_{\mathrm{x}} \mathrm{Ga}_{1-\mathrm{x}} \mathrm{N}$ samples. The experimental curve and the fitting are shown by dotted and solid lines, respectively.

The spectra of the $\mathrm{In}_{\mathrm{y}} \mathrm{Al}_{1-\mathrm{y}} \mathrm{N}$ samples are shown in Fig. 3. The fitting results for the $\operatorname{In}_{\mathrm{x}} \mathrm{Ga}_{1-\mathrm{x}} \mathrm{N}$ and $\operatorname{In}_{\mathrm{y}} \mathrm{Al}_{1-\mathrm{y}} \mathrm{N}$ samples are listed in Tables 1 and 2, respectively. A comparison of the calculated $n n$ distances with results published in the literature is depicted in Figs. 4 and 5. The values expected according to Vegard's law are plotted with a dashed line. As shown in Figs. 4 and 5 the calculated In-N and Incation distances, in both the $\operatorname{In}_{\mathrm{x}} \mathrm{Ga}_{1-\mathrm{x}} \mathrm{N}$ and $\operatorname{In}_{\mathrm{y}} \mathrm{Al}_{1-\mathrm{y}} \mathrm{N}$ samples, are in very good agreement with the theoretically predicted values. More specifically, the In-N distance depends on the In concentration in both the $\operatorname{In}_{\mathrm{x}} \mathrm{Ga}_{1-\mathrm{x}} \mathrm{N}$ (Fig. 4(a)) and $\operatorname{In}_{\mathrm{y}} \mathrm{Al}_{1-\mathrm{y}} \mathrm{N}$ layers (Fig. 5(a)) but the bondlength variation is much smaller than that predicted by Vegard's law. Contrary to that, the In-cation distances have a stronger dependence on the In concentration. More specifically, the In- $\mathrm{Ga}$ distance in the $\operatorname{In}_{\mathrm{x}} \mathrm{Ga}_{1-\mathrm{x}} \mathrm{N}$ samples (Fig. 4(b)) and the $\mathrm{In}-\mathrm{Al}$ distance in the $\mathrm{In}_{\mathrm{y}} \mathrm{Al}_{1-\mathrm{y}} \mathrm{N}$ (Fig. 5(b)) samples agree well with the values predicted by Vegard's law, while the In-In distances deviate from the predicted values in the samples where the In content is less than $70 \%$ (Figs. 4(c) and 5(b)). These results depict that the alloying- 
induced stress, i.e. due to substitution of cations with atoms of significantly different atomic radii, is mainly accommodated by bond bending rather than bond stretching.

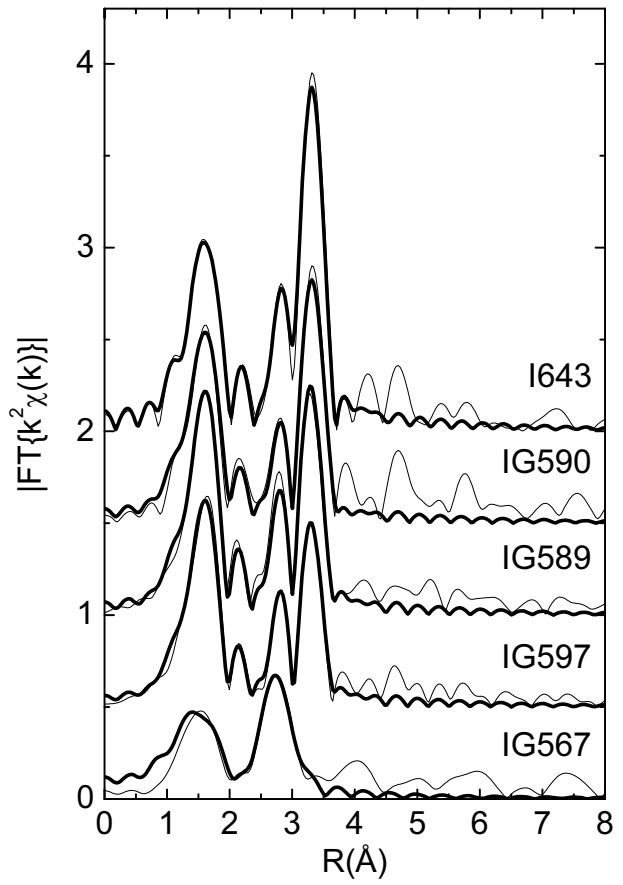

Figure 2 Fourier transforms of the $\mathrm{k}^{2}$ weighted $\chi(\mathrm{k})$ spectra of the $\mathrm{InN}$ and $\mathrm{In}_{\mathrm{x}} \mathrm{Ga}_{1-\mathrm{x}} \mathrm{N}$ samples shown in Fig. 1. The experimental curve and the fitting are shown by thin and thick solid lines, respectively.

Finally, the values of the DWF for the $\operatorname{In}_{x} \mathrm{Ga}_{1-\mathrm{x}} \mathrm{N}$ samples with $x \geq 0.7$ do not show significant variation. The high values of the DWF for the 1st and 2 nd $n n$ shell of the sample with $\mathrm{x}=0.07$ can be attributed to the wide bond angle distribution around In in samples with small In content [10].

Table 1 Fitting results for the $\mathrm{InN}$ and $\mathrm{In}_{\mathrm{x}} \mathrm{Ga}_{1-\mathrm{x}} \mathrm{N}$ samples. $\mathrm{R}$ and $\sigma^{2}$ stand for the $n n$ distance (in $\AA$ ) and the DWF (in $\AA^{2}$ multiplied by $10^{3}$ ). The errors listed are the uncertainties provided by the fitting program. The amplitude reduction factor and the shift of the energy origin were commonly iterated for all the samples and were found equal to 1.0 and $-1.01 \pm 0.26 \mathrm{eV}$, respectively.

\begin{tabular}{|c|c|c|c|c|c|}
\hline & \multicolumn{5}{|c|}{$\operatorname{In}_{\mathrm{x}} \mathrm{Ga}_{1-\mathrm{x}} \mathrm{N}$ samples } \\
\hline & IG567 & IG597 & IG589 & IG590 & I643 \\
\hline & \multicolumn{5}{|c|}{ In fraction } \\
\hline & 0.07 & 0.7 & 0.8 & 0.9 & 1 \\
\hline$\overline{\mathbf{R}_{\text {In-N }}}$ & $2.09 \pm 0.01$ & $2.13 \pm 0.01$ & $2.13 \pm 0.01$ & $2.14 \pm 0.01$ & $2.15 \pm 0.01$ \\
\hline$\sigma_{\text {In-N }}^{2}$ & $16 \pm 5$ & $4.2 \pm 0.8$ & $3.0 \pm 1.0$ & $4.8 \pm 1.8$ & $4.4 \pm 1.2$ \\
\hline$\overline{\mathbf{R}_{\text {In-Ga }}}$ & $3.22 \pm 0.04$ & $3.45 \pm 0.02$ & $3.43 \pm 0.03$ & $3.45 \pm 0.09$ & \\
\hline$\sigma_{\text {In-Ga }}^{2}$ & $14 \pm 3$ & $5.5 \pm 2.0$ & $6.5 \pm 3.6$ & $4.5 \pm 2.1$ & - \\
\hline$\overline{\mathbf{R}_{\text {In-In }}}$ & $3.31 \pm 0.01$ & $3.46 \pm 0.01$ & $3.47 \pm 0.01$ & $3.50 \pm 0.01$ & $3.51 \pm 0.01$ \\
\hline$\sigma_{\text {In-In }}^{2}$ & $4 \pm 9$ & $6.2 \pm 0.9$ & $6.6 \pm 0.1$ & $7.1 \pm 0.9$ & $5.6 \pm 0.3$ \\
\hline
\end{tabular}
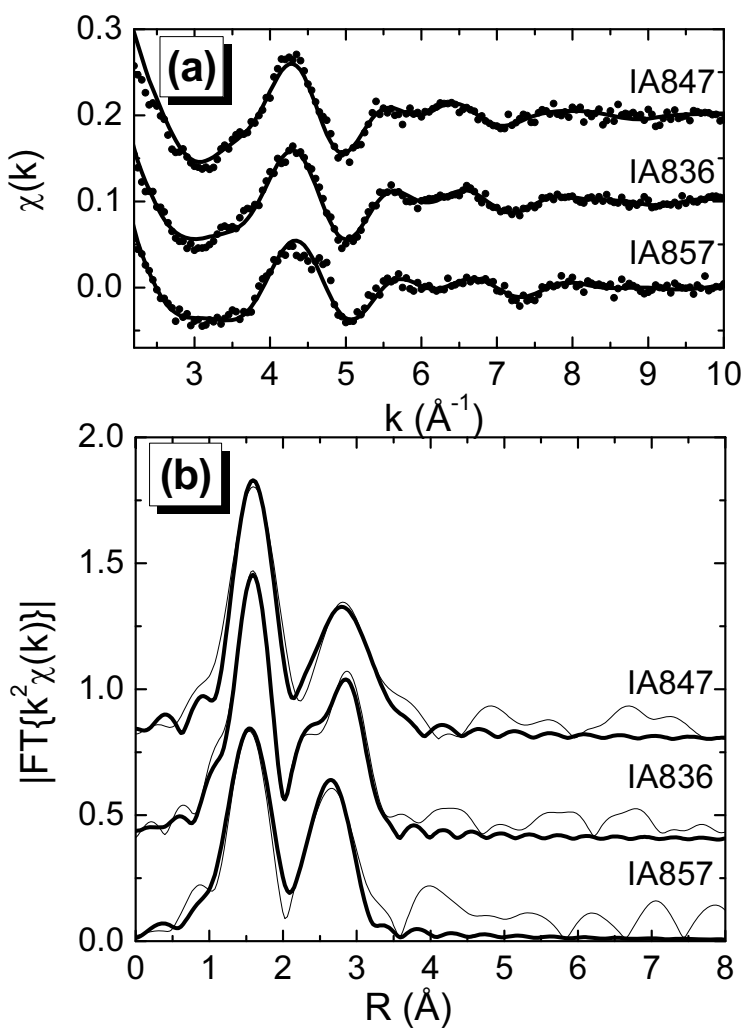

Figure 3 (a) $\chi(\mathrm{k})$ spectra and (b) the corresponding Fourier transforms of the $\mathrm{k}^{2}$ weighted $\chi(\mathrm{k})$ spectra of the $\mathrm{In}_{\mathrm{y}} \mathrm{Al}_{1-\mathrm{y}} \mathrm{N}$ samples. The experimental curve is shown in (a) by dots and (b) by thin solid line while the fitting is plotted with thick solid line.

Table 2 Fitting results of the $\operatorname{In}_{\mathrm{y}} \mathrm{Al}_{1-\mathrm{y}} \mathrm{N}$ samples. $\mathrm{R}$ is the $n n$ distance (in $\AA$ ), $\sigma^{2}$ is the DWF (in $\AA^{2}$ multiplied by $10^{3}$ ) and $\Delta \mathrm{E}_{0}$ is the shift of the energy origin in $\mathrm{eV}$. The errors listed are the uncertainties provided by the fitting program. The amplitude reduction factor was simultaneously iterated for all the samples and was found equal to 0.85 .

\begin{tabular}{|c|c|c|c|}
\hline & \multicolumn{3}{|c|}{$\mathrm{In}_{\mathrm{y}} \mathbf{A} \mathbf{l}_{1-\mathrm{y}} \mathrm{N}$ samples } \\
\hline & IA857 & IA836 & IA847 \\
\hline & \multicolumn{3}{|c|}{ In fraction } \\
\hline & 0.07 & 0.12 & 0.25 \\
\hline$\overline{\mathbf{R}_{\text {In-N }}}$ & $2.08 \pm 0.01$ & $2.10 \pm 0.01$ & $2.12 \pm 0.02$ \\
\hline$\sigma_{\text {In-N }}^{2}$ & $5.2 \pm 0.8$ & $2.5 \pm 0.5$ & $1.6 \pm 1.5$ \\
\hline$\overline{\mathbf{R}_{\text {In-AI }}}$ & $3.17 \pm 0.01$ & $3.20 \pm 0.01$ & $3.26 \pm 0.02$ \\
\hline$\sigma_{\text {In-Al }}^{2}$ & $12.1 \pm 1.0$ & $10.3 \pm 0.7$ & $10.5 \pm 2.5$ \\
\hline $\mathbf{R}_{\text {In-In }}$ & $3.17 \pm 0.03$ & $3.26 \pm 0.01$ & $3.37 \pm 0.04$ \\
\hline$\sigma_{\text {In-In }}^{2}$ & $7.0 \pm 3.5$ & $2.2 \pm 0.7$ & $6.8 \pm 4.9$ \\
\hline$\overline{\Delta \mathbf{E}_{0}}$ & \multicolumn{2}{|c|}{$0.55 \pm 0.3$} & $2.93 \pm 1.4$ \\
\hline
\end{tabular}

4 Conclusions The nearest neighbour distances of In in In-rich $\operatorname{In}_{\mathrm{x}} \mathrm{Ga}_{1-\mathrm{x}} \mathrm{N}$ and Al-rich $\operatorname{In}_{\mathrm{y}} \mathrm{Al}_{1-\mathrm{y}} \mathrm{N}$ epilayers determined by means of EXAFS spectroscopy are in agree- 
ment with the values predicted by theoretical calculations. The In-N distances are found to resist the alloying-induced reduction, predicted by Vegard's law. Contrary to that, the In-Ga and In-Al distances are more flexible and they obey Vegard's law. The In-In distance deviates from the values predicted by Vegard's law for In concentration less than $70 \%$.
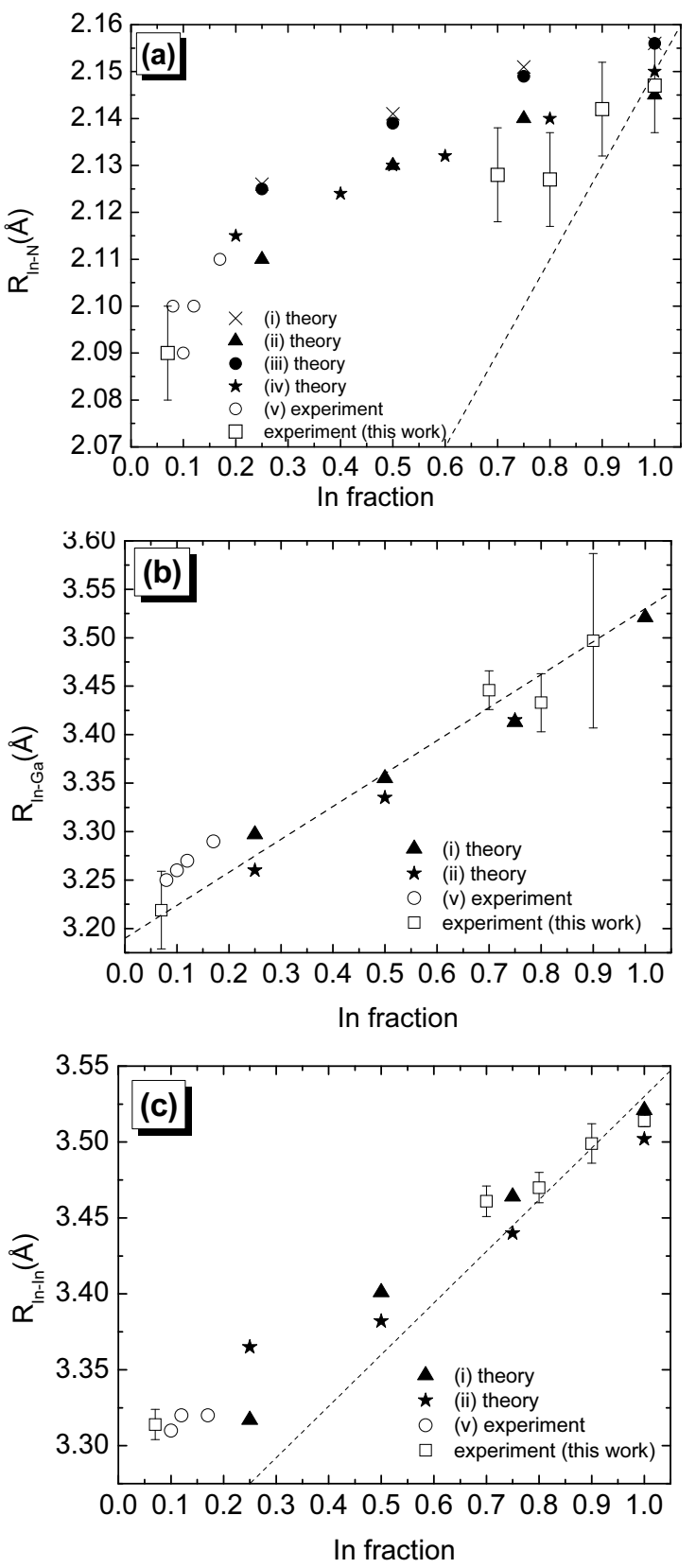

Figure 4 Comparison of the experimentally determined (a) In-N, (b) In-Ga and (c) In-In distances with theoretically calculated values for the $\operatorname{In}_{\mathrm{x}} \mathrm{Ga}_{1-\mathrm{x}} \mathrm{N}$ alloys. The published results are from (i) Matilla and Zunger [7], (ii) Ferhat and Bechstedt [8] (iii) Takayama et al. [9], (iv) Saito and Arakawa [10], and (v) Katsikini et al. [11]. The dashed lines correspond to the values predicted by Vegard's law.
These findings indicate that the stress induced in the lattice due to alloying is accommodated mainly by bond bending rather with cation- $\mathrm{N}$ bond stretching mechanisms, in accordance with the large internal stress parameters, $\zeta_{\mathrm{h}}$, which are equal to $0.88,0.66$ and 0.76 for $\operatorname{InN}, \mathrm{GaN}$ and AlN, respectively [12]

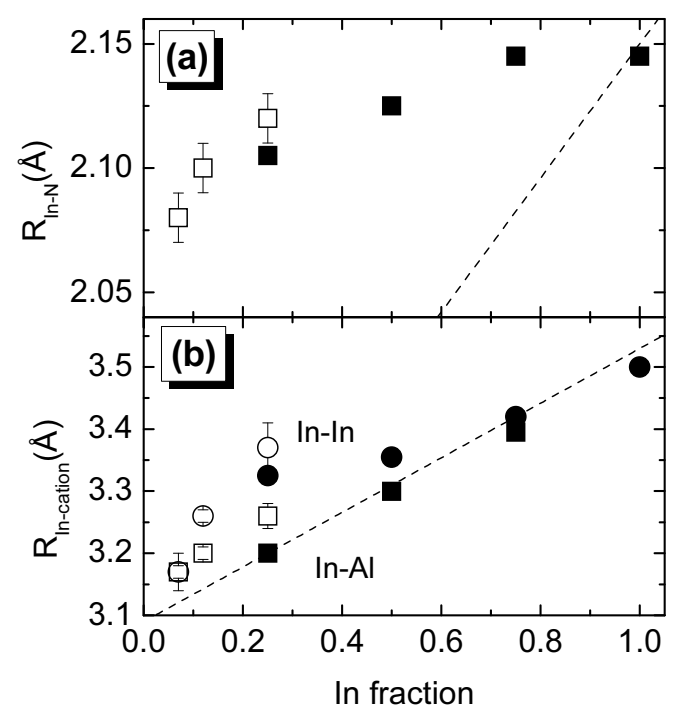

Figure 5 Comparison of the experimentally determined (a) In-N, (b) In-cation distances with theoretically calculated values in the $\mathrm{In}_{\mathrm{y}} \mathrm{Al}_{1-\mathrm{y}} \mathrm{N}$ samples. Solid symbols correspond to the theoretically calculated values by Ferhat and Bechstedt [8] and the open symbols correspond to the values determined here. The dashed lines correspond to the values predicted by Vegard's law.

Acknowledgements This work was supported by the EC under the contract MRTN-CT-2004-005583 (PARSEM). The measurements at HASYLAB were financially supported by the EC IA-SFS program under the contract RII3-CT-2004506008 .

\section{References}

[1] V. Yu. Davydov, A. A. Klochikhin, R. P. Seisyan, V. V. Emtsev, S. V. Ivanov, F. Bechstedt, J. Furthmüller, H. Harina, A. V. Mudryi, J. Aderhold, O. Semchinova, and J. Graul, phys. stat. sol. (b) 229, R1 (2002).

[2] K. Kuzmík, A. Kostopoulos, G. Konstantinidis, J.-F., Carlin, A. Georgakilas, and D. Pogany, IEEE Trans. Electron Devices 53, 422 (2006).

[3] J. C. Mikkelsen, Jr. and J. B. Boyce, Phys. Rev. B 28, 7130 (1983).

[4] E. Iliopoulos, A. Georgakilas, E. Dimakis, A. Adikimenakis, K. Tsagaraki, M. Androulidaki, and N. T. Pelekanos, phys. stat. sol. (a) 203, 102 (2006).

[5] M. S. Shur and M. Asif Khan, MRS Bull. 22, 44 (1997).

[6] A. L. Ankudinov, B. Ravel, J. J. Rehr, and S. D. Conradson, Phys. Rev. B 58, 7565 (1998).

[7] T. Mattila and A. Zunger, J. Appl. Phys. 85, 160 (1999).

[8] M. Ferhat and F. Bechstedt, Phys. Rev. B 65, 075213 (2002). 
[9] T. Takayama, M. Yuri, K. Itoh, T. Baba, and J. S. Harris, Jr., J. Appl. Phys. 88, 1104 (2000).

[10] T. Saito and Y. Arakawa, Phys. Rev. B 60, 1701 (1999).

[11] M. Katsikini, E. C. Paloura, F. Boscherini, F. D' Acapito, C. B. Lioutas, and D. Doppalapudi, Nucl. Instrum. Meth. B 200, 114 (2003).

[12] A. F. Wright, J. Appl. Phys. 82, 2833 (1997). 